\title{
The Relationship Between Extracellular Matrix Proteins and Germ Cell Apoptosis in Balb/C Mouse Testis Following Experimental Hypothyroidism
}

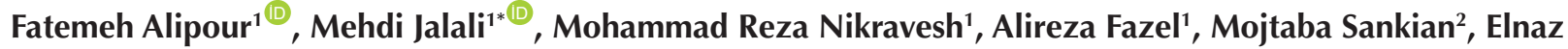 \\ Khordad $^{1}$
}

\begin{abstract}
Objectives: Dysfunction of the thyroid gland has a negative effect on the male reproductive system. Studies also show that extracellular matrix (ECM) components play an essential role in testicular development and function. In hypothyroidism, there is a significant disruption in the ECM structure of mammalian tissues. In addition, notable changes have been reported in the germ cell population under a hypothyroid state. This study aimed to investigate the relationship between ECM proteins and apoptosis of testicular germ cells due to hypothyroidism.

Materials and Methods: In the present experimental study, 20 male Balb/C mice were divided into control and hypothyroid groups. The hypothyroid group received 0.05\% 6-n-propyl-2-thiouracil (PTU) through drinking water for 35 days. Finally, real-time polymerase chain reaction, immunohistochemistry, periodic acid-Schiff (PAS) staining, terminal transferase-mediated dUTP nickend labelling (TUNEL) assay, and biochemical measurements were performed after hypothyroidism confirmation.

Results: Laminin $\alpha 5$ and collagen IV mRNA levels were upregulated in the hypothyroid group compared to the controls $(P<0.05)$. Further, a strong immunoreactivity of collagen IV and laminin $\alpha 5$ was observed in the basement membrane (BM) of hypothyroid mice $(P<0.05)$. In contrast, there was no significant difference between the case and control groups regarding PAS staining. The number of TUNEL-positive germ cells in hypothyroid mice increased significantly compared to control mice. Moreover, PTU administration reduced superoxide dismutase activity while increasing the malondialdehyde level $(P<0.05)$. Eventually, no significant difference was found between the two groups in terms of thiol content.

Conclusions: Based on the results of the present study, hypothyroidism can cause changes in BM components and increase the apoptosis of germ cells by inducing lipid peroxidation and reducing the activity of antioxidant defense molecules.

Keywords: Hypothyroidism, Laminin $\alpha 5$, Collagen IV, Germ cell, Apoptosis
\end{abstract}

\section{Introduction}

The most important roles of thyroid hormone (TH) are the regulation, differentiation, metabolism, and normal function of body tissues (1-3). Changes in TH levels cause either hypothyroidism or hyperthyroidism (4). One of the most common thyroid disorders is hypothyroidism, which is associated with decreased TH levels $(5,6)$. Functional and anatomical changes of the thyroid gland cause different kinds of hypothyroidism $(7,8)$. According to the clinical presentation, hypothyroidism is classified into mild and severe forms which are defined as subclinical and overt hypothyroidism, respectively. Thyroid-stimulating hormone (TSH) levels in overt primary hypothyroidism are high while thyroxine (T4), triiodothyronine, and (T3) levels are low. Subclinical hypothyroidism is characterized by an elevation in the TSH level but with a normal level of T3 and T4. Furthermore, congenital hypothyroidism is a $\mathrm{TH}$ deficiency condition that is observed at birth due to a defect in the thyroid gland development or impaired $\mathrm{TH}$ biosynthesis $(7,8)$. A large body of data indicates that an altered thyroid status in mammals adversely affects many organs and tissues (9). Although it was long thought that the testis was an unresponsive tissue to $\mathrm{TH}$, studies in the past two decades have shown that it is a hormoneresponsive organ, and $\mathrm{TH}$ is important in the regulations of growth, proliferation, and differentiation of Sertoli, germ, and Leydig cells and testicular functions $(1,2)$. Previous studies demonstrated that thyroid dysfunction could lead to morphological and functional abnormalities in the testis. Additionally, in several reports, disturbance in the $\mathrm{TH}$ could adversely affect male fertility and spermatogenesis $(1,10)$.

Further, it is now well proved that extracellular matrix (ECM) is more than an inert scaffold around cells that are involved in the development, differentiation function of the testis, and eventually, spermatogenesis (11-16). ECM

Received 15 July 2018, Accepted 23 October 2018, Available online 24 November 2018

${ }^{1}$ Department of Anatomy and Cellular Biology, Faculty of Medicine, Mashhad University of Medical Sciences, Mashhad, Iran. ${ }^{2}$ Bou-Ali Research Institute, Immunology Research Center, Mashhad University of Medical Sciences, Mashhad, Iran.

*Corresponding Author: Mehdi Jalali, Tel: (+98) 9355164600, Email: Jalalim@mums.ac.ir 


\section{Key Message}

- Male reproduction system is adversely affected by thyroid gland dysfunction

- ECM plays a critical role in testicular development, growth, and function.

- Hypothyroidism as an underactive thyroid condition can cause detrimental changes in the components of ECM and increase the apoptotic of germ cells.

is consisted of glycoproteins and proteoglycans filling the interstitial space of seminiferous tubules (15). As part of $\mathrm{ECM}$, the basement membrane (BM) surrounding the basal surface of seminiferous epithelium is synthesized by the cooperation between the Sertoli and peritubular myoid cells $(6,16-20)$. BM components in the testis have also been indicated to modulate the function and survival of Sertoli cells (20). Interactions between Sertoli, Leydig, myoid, and germ cells are necessary for the spermatogenesis process (16). The BM surrounding the seminiferous tubules contains biologically active components including laminin and collagen IV, along with heparan sulfate proteoglycan and entactin/nidogen which are localized directly below the Sertoli cells $(17-19,21)$. Laminin protein is one of the most important components of ECM. Laminin plays a key role in BM assembly because it is formed earlier in the embryo and interacts with other cells. Moreover, it has a flexible and large structure including three non-identical polypeptide chains called $\alpha, \beta$, and $\gamma$. These chains are organized in the form of an asymmetric cross supported by disulfide bonds. Minimally, 15 isoforms of laminin have been identified, mainly expressed and synthesized during fetal and adult lifelong. Laminin regulates cell signaling and adhesion via binding to integrins $(14,15,17,22,23)$.

Collagen IV as another important component of the $\mathrm{BM}$ of the seminiferous tubule is considered to play a structural role in all basal lamina. Collagen has been regarded to promote cell adhesion, differentiation, and migration. Collagen IV consists of three a chains that form a triple helical structure by the bandings of monomers. Genetically, six different a chains exist, including, $\alpha$ l (IV) and $\alpha 2$ (IV) chains that are ubiquitously present in BM, as well as $a 3-\alpha 6$ (IV) chains with a more restricted distribution $(12,14,15,23)$. It is well established that alterations in specific BM components likely affect the function and structure of the deposited BM (20). Additionally, several reports have indicated that disruption in the BM can perturb the cross-talks between the ECM and Sertoli cells. Furthermore, using the antibodies against laminin and collagen IV could disturb spermatogenesis $(12,15,18,23)$. THs have been demonstrated to influence ECM metabolism and protein secretion (24). Moreover, in vivo and in vitro treatment with $\mathrm{T} 3$ resulted in remodeling the BM surrounding the seminiferous epithelium (20). Additionally, a direct correlation has been reported between developmental changes in the BM composition and the delay in the development of germ cell and Sertoli cell maturation in the testis of the hypothyroid rats (19). On the other hand, previous research represents that germ cell apoptosis plays a vital role in controlling sperm production by Sertoli cells during spermatogenesis in puberty or adulthood (25).

Alterations in testis physiology under a hypothyroid condition cause hampered fertility as evidenced by reduced total viable germ cells. As a specific type of programmed cell death, apoptosis is necessary for maintaining testicular homeostasis $(26,27)$. Apoptosis in male germ cells can occur in any phase of spermatogenesis from fetal life to adulthood. In adulthood, germ cell apoptosis is involved in removing damaged cells due to chemotherapeutic agents, exposure to toxicants, hormonal factors, and genetic mutations. The evidence indicated many apoptotic germ cells in infertile men's testes (28). However, little is known about the effect of hormonal factors on germ cell apoptosis (25). The normal TH level was reported to prevent cerebellar apoptosis whereas hypothyroidism increased apoptosis and promoted the pro-apoptotic Bax expression (29). According to evidence, hypothyroidism may alter the structure of mitochondria, releasing apoptogenic proteins from the mitochondria, eventually leading to apoptosis (30). TH has been considered as one of the main regulators of oxygen consumption and mitochondrial energy metabolism (26). TH plays a crucial role in preserving the balance between antioxidant molecules and reactive oxygen species (ROS) production in various tissues such as the testis. Alterations in the level of TH cause oxidative stress (OS) in the tissues through modulating antioxidant defenses (3). Some studies indicated that there is a relationship between increased OS in the testis and hypothyroidism $(31,32)$. OS is also one of the most critical factors in causing germ cell apoptosis $(26,27,31)$. Therefore, the purpose of this study was to examine the relationship between ECM proteins and germ cell apoptosis following experimental hypothyroidism.

\section{Materials and Methods}

\section{Animals and Study Design}

Our research was performed based on the instructions of the National Institute for Care and Use of Experimental Animals (NIH Publications No. 80-23, revised 1978) and approved by the Ethical Committee (approval NO. IR.MUMS.fm.REC.1394.230) of Mashhad University of Medical Sciences, Iran. Based on the aim of the study, 20 Balb/C mice (approximately 9 weeks old and weighing 20-25 g) were purchased from the Animal Center of Mashhad University of Medical Sciences. The animals were housed under standard conditions (12 light-dark cycles), humidity (55-65\%), and at controlled temperature $\left(22-24^{\circ} \mathrm{C}\right)$, with ad libitum access to food and water. One week after adaptation, the animals were divided into two hypothyroid and control groups $(\mathrm{n}=10)$, and those in the control group received no treatment. 
Induction of Hypothyroidism

In the present study, hypothyroidism was induced in the animals by administrating $0.05 \%$ (w/v) 6-n-propyl2-thiouracil (PTU, Iran Hormone Company, Iran) in their drinking water for 35 days. At the end of the experiment period, the animals were deeply anesthetized with chloroform and then the blood samples were transcardinally collected to determine hypothyroidism using the chemiluminescent immunoassay method. Then, the animals were sacrificed, and the testes were removed to be prepared for immunohistochemistry, real-time PCR, periodic acid-Schiff (PAS) staining, terminal transferasemediated dUTP nick-end labelling (TUNEL) assay, and biochemical measurements.

\section{RNA Extraction and cDNA Synthesis}

Total RNA was isolated from the testis by the RNA Extraction Kit (Parstous Corporation, Iran) according to the manufacturer's recommendations. Briefly, first, the testis was homogenized in the RL solution. Then, $150 \mu \mathrm{L}$ of chloroform was added and centrifuged at $4^{\circ} \mathrm{C}$ for 12 minutes. Next, $400 \mu \mathrm{L}$ of the upper phase containing RNA was transferred into a new tube, and an equal volume of $70 \%$ ethanol was also added to the mixture and then centrifuged at $4^{\circ} \mathrm{C}$ for 1 minute. Thereafter, $700 \mu \mathrm{L}$ and 500 $\mu \mathrm{L}$ of $\mathrm{PW}$ were added and centrifuged at $4^{\circ} \mathrm{C}$ for 2 minutes, respectively. Finally, $50 \mu \mathrm{L}$ of diethylpyrocarbonate (DEPC) water was used and centrifuged to wash RNA off the column. The quantity and quality of the total RNA was checked by a spectrophotometer (BioTek, Epoch Microplate Spectrophotometer UV-Vis, USA) at ratio A260/A280 nm ), and 1\% agarose gel for the visualization of $18 \mathrm{~S}$ and $28 \mathrm{~S}$ ribosomal bands, respectively.

\section{cDNA Synthesis}

cDNA was synthesized using a cDNA synthesis kit (Parstous Corporation, Iran) according to the manufacturer's instructions. In brief, $0.5 \mu \mathrm{L}$ of RNA was reverse transcribed with $1 \mu \mathrm{L}$ of oligo $(\mathrm{dt})$ and $8.5 \mu \mathrm{L}$ of DEPC water. Then, the mixture was incubated at $65^{\circ} \mathrm{C}$ for 5 minutes and then immediately chilled on ice. Next, $10 \mu \mathrm{L}$ of RT-premix was added to the mixture (volume reaction $=20 \mu \mathrm{L}$ ) and incubated at $25^{\circ} \mathrm{C}$ and $50^{\circ} \mathrm{C}$ for 10 and 60 minutes, respectively. Finally, the enzyme activity was inactivated by heating at $70{ }^{\circ} \mathrm{C}$ for 10 minutes, and then the synthesized cDNA samples were maintained at $-70^{\circ} \mathrm{C}$.
Real-Time Polymerase Chain Reaction

The real-time polymerase chain reaction (RT-PCR) technique was conducted to assess the change in collagen IV, the a5 laminin, and GAPDH gene expression. The RT-PCRs were established in duplicate to evaluate the alteration in collagen IV and laminin a5 genes, and GAPDH was selected as a reference gene. The reactions were performed by SYBER Green/ROX master mix kit (Parstous Corporation, Iran). Each reaction mixture consisted of $10 \mu \mathrm{L}$ of master mix, $1 \mu \mathrm{L}$ of each of the forward and the reverse primers (Table 1), $7.1 \mu \mathrm{L}$ distilled water, $0.4 \mu \mathrm{L}$ of Rox dye, and $0.5 \mu \mathrm{L}$ of the cDNA templates (volume reaction $=20 \mu \mathrm{L}$ ). The amplification cycle conditions included an initial denaturation step (one cycle at $94^{\circ} \mathrm{C}$ for 10 minutes) and then followed by 35 cycles (denaturation at $95^{\circ} \mathrm{C}$ for 30 seconds; annealing at $60^{\circ} \mathrm{C}$ for 1 minute, and extension at $72^{\circ} \mathrm{C}$ for 30 seconds). Eventually, the relative gene expression was calculated using the comparative CT method: $2^{-\triangle \Delta C T}$ (33).

\section{Immunohistochemistry Method}

This method was performed to immunolocalize laminin a5 and collagen IV proteins in the BM of the seminiferous tubules of groups. Briefly, deparaffinized sections were rehydrated by the descending grade of ethanol and then washed in phosphate buffer saline solution ( $\mathrm{PBS}, \mathrm{pH}=7.4$ ). Then, heat-induced antigen retrieval was conducted with PBS/ethylenediaminetetraacetic acid (EDTA) solution buffer for 30 minutes. Next, the sections were immersed in $0.3 \% \mathrm{H}_{2} \mathrm{O}_{2}$ and methanol to inhibit endogenous peroxidase activity. After washing in PBS, nonspecific bindings were blocked with $10 \%$ goat serum and bovine serum albumin $1 \%$ in PBS. Afterward, the sections were incubated with laminin a5 (1:100 dilution; Abcam, USA) and collagen IV (1:200 dilution; Abcam, USA) as primary antibodies overnight at $4^{\circ} \mathrm{C}$. In the next day, the sections were washed in PBS, and then horseradish peroxidase (HRP) conjugated secondary antibody (1:400 dilution; Abcam, USA) was applied at $37^{\circ} \mathrm{C}$ for 2 hours. Finally, 3-diamianobenzidine (DAB) containing $0.01 \% \mathrm{H}_{2} \mathrm{O}_{2}$ was used to visualize the reactions, then the sections were counterstained with hematoxylin, dehydrated, cleared, and mounted as well. The intensity of immunoreactivities between the groups was assessed semi-quantitatively through the grading scales as weak $(+)$, moderate $(++)$, strong $(+++)$, and very strong $(++++)$ reactions. The

Table 1. Sequences of Applied Primers for the RT-PCR

\begin{tabular}{|c|c|c|c|}
\hline Gene & Primer Sequences & Product Size (bp) & Annealing Temperature $\left({ }^{\circ} \mathrm{C}\right)$ \\
\hline Collagen IV & $\begin{array}{l}\text { 5'-AAGCTGTAAGCATTCGCGTAGTA-3'(R) } \\
\text { 5'- ATTCCTTTGTGATGCACACCAG-3'(F) }\end{array}$ & 107 & 58 \\
\hline Laminin $\alpha 5$ & $\begin{array}{l}\text { 5'-TACCAACGAAGGGCTGCG- 3'(R) } \\
5^{\prime}-\text { CGTCCCACAGGAATAGGCT- 3'(F) }\end{array}$ & 109 & 58 \\
\hline GAPDH & $\begin{array}{l}\text { 5'- CTGTAGCCATATTCATTGTCATACCA-3'(R) } \\
\text { 5'-AACTCCCATTCTTCCACCTTTG-3'(F) }\end{array}$ & 385 & 58 \\
\hline
\end{tabular}

Note. GAPDH: Glyceraldehyde 3-phosphate dehydrogenase; RT-PCR: Real-time polymerase chain reaction. 
locations served as positive staining where the expressed laminin a5 and collagen IV appeared in brown. All the samples were graded blindly by two observers (33). The incubated sections in PBS without primary antibodies served as negative controls.

\section{PAS Staining}

After routine histological tissue processing, the deparaffinized testicular sections were washed in PBS and then placed into periodic acid 1\% solution for 5 minutes. Next, the sections were stained with Schiff's reagent for 2-5 minutes. In the next step, the sections were counterstained with Harris hematoxylin and then, dehydrated, cleared, and mounted, and finally, the intensity of reactions was scored as described above (34).

\section{TUNEL Assay}

A terminal transferase-mediated dUTP nick-end labelling assay (TUNEL) kit (Roche, Germany) was used to detect apoptotic germ cells in testicular sections. First, the sections were deparaffinized, rehydrated, and rinsed in $0.1 \mathrm{M}$ PBS, and then incubated with $20 \mu \mathrm{g} / \mathrm{mL}$ proteinase $\mathrm{K}$ (Roche, Germany) for 20 minutes. To inactivate endogenous peroxidase, the sections were treated with $3 \%$ $\mathrm{H}_{2} \mathrm{O}_{2}$ in methanol. After PBS washing, the sections were incubated in the reaction mixture containing terminal deoxynucleotidyl transferase and the deoxynucleotide mixture overnight at $4^{\circ} \mathrm{C}$. In addition, the sections were treated with the HRP conjugated secondary antibody for 2 hours at $37^{\circ} \mathrm{C}$ and then treated with DAB solution containing $0.01 \% \quad \mathrm{H}_{2} \mathrm{O}_{2}$. Finally, the sections were counterstained with hematoxylin, dehydrated, cleared, and mounted as well. Apoptotic germ cells appeared in dark brown. The sections were incubated with the TUNEL reaction mixture, but they served as negative controls without terminal transferase. The numbers of TUNEL positive cells were counted using Image J software. The numbers of positive cells per unit area (NA) in the testis were calculated by the following formula:

$$
D=\sum_{i=1}^{n} X_{i}
$$

where $\Sigma Q$ indicates the sum of the counted positive germ cells that were visible in the sections. Further, $a / f$ and $\Sigma P$ are the area related to each frame and the sum of frames that were associated with points hitting space, respectively (35).

\section{Biochemical Assessment}

The testicular tissue was examined for malondialdehyde (MDA) concentration, total thiol content, and superoxide dismutase (SOD) activity. MDA levels as an index of LPx were measured to determine lipid peroxidation (LPx). MDA reacts with thiobarbituric acid (TBA) as a thiobarbituric acid reactive substance and the production of a red colored-complex with a peak absorbance at 535 $\mathrm{nm}$. For this purpose, $2 \mathrm{~mL}$ of thiobarbituric acid (TBA)/ trichloroacetic acid (TCA) and hydrochloric acid $(\mathrm{HCl})$ reagents were added to a $1 \mathrm{~mL}$ homogenate tissue and then incubated in a $100^{\circ} \mathrm{C}$ water bath for 45 minutes. After cooling and centrifuging, the supernatant was separated, and the absorbance was read at $535 \mathrm{~nm}$. The concentration of MDA was calculated as described formerly (36).

The total thiol content was measured via DTNB (2, $2^{\prime}$-dinitro-5,5'-dithiodibenzoic acid) as the reagent. This reagent reacts to $\mathrm{SH}$ (sulfhydryl) groups and yields a yellow-colored complex with a peak absorbance at 412 $\mathrm{nm}$. In brief, $1 \mathrm{~mL}$ Tris- EDTA buffer $(\mathrm{pH}=8.6)$ was added to $50 \mu \mathrm{L}$ testis homogenate in $1 \mathrm{~mL}$ cuvettes, and the absorbance was then read at $412 \mathrm{~nm}$ against TrisEDTA buffer alone. Next, $20 \mu \mathrm{L}$ DTNB reagents ( $10 \mathrm{mM}$ in methanol) were added and the absorbance was read again after 15 minutes at room temperature. DTNB absorbance was also read as a blank. The calculation of the total thiol concentration (mM) was previously described (36).

The SOD activity was measured as previously described by Madesh and Balasubramanian. The mentioned method is a colorimetric assay consisting of the generation of superoxide by pyrogallol autoxidation and the inhibition of the superoxide-dependent reduction of the tetrazolium dye MTT (3-(4, 5-dimethylthiazol-2-yl) 2, 5 -diphenyltetrazolium bromide) to formazan by SOD at $570 \mathrm{~nm}$. One SOD activity unit was defined as the amount of enzyme causing $50 \%$ inhibition in the reduction rate of the MTT $(36,37)$.

\section{Statistical Analysis}

The data were analyzed by SPSS software (version 16), and a $P$ value of less than 0.05 was considered statistically significant. The non-parametric Mann-Whitney test was used to analyze the results of immunohistochemistry and PAS staining. Additionally, an independent t-test was applied to analyze the results of RT-PCR, the TUNEL assay, and biochemical parameters.

\section{Results}

\section{Serum Hormones Profile}

Based on the findings of the study, the serum levels of total T4 remained low in the hypothyroid group compared to the control group whereas the TSH level increased in the hypothyroid group in comparison to the controls, confirming the hypothyroid status of PTU-administered mice (Table 2, $P<0.05$ ).

Hypothyroidism Alters Laminin $\alpha 5$ and Collagen IV Gene Expression

The quantitative RT-PCR was used to evaluate laminin a5 and collagen IV mRNAs expression. The results showed that the levels of laminin a5 mRNA in the hypothyroid group significantly increased compared to the control group $(P<0.001$, Figure $1 \mathrm{~A})$. Meanwhile, collagen IV mRNAs were also highly expressed in the hypothyroid 
Table 2. Impact of PTU Treatment on Serum Total T4 and TSH Levels

\begin{tabular}{lcc}
\hline Variables & Control & Hypothyroid \\
\hline $\mathrm{T} 4(\mu \mathrm{g} / \mathrm{dL})$ & $8.02 \pm 1.27$ & $3.4 \pm 0.47^{\mathrm{a}}$ \\
$\mathrm{TSH}(\mu \mathrm{IU} / \mathrm{mL})$ & $2.15 \pm 0.35$ & $6.67 \pm 1.12^{\mathrm{a}}$ \\
\hline
\end{tabular}

Note. SD: Standard deviation; PTU: 6-n-propyl-2-thiouracil; TSH: Thyroidstimulating hormone. Data are expressed as the mean \pm SD. Superscript letter (a) indicates a statistically significant different $(P<0.05)$. Comparisons are between control and hypothyroid groups.

mice compared to the control ones $(P<0.001$, Figure 1B).

Hypothyroidism Leads to Alterations in the Immunoreactivity of the Basement Membrane of the Testis

The immunohistochemistry technique was employed to determine the distribution of laminin a5 and collagen IV proteins in BM seminiferous tubules. The intensity of the reaction was scored according to color opacity. The results revealed that the laminin a 5 reaction significantly increased in the BM of the hypothyroid mice compared to the control group $(P<0.001$, Figure $2 \mathrm{~A}-\mathrm{C})$. Furthermore, a significant increase was observed in the immunoreactivity of collagen IV in the hypothyroid group in comparison to the control group $(P<0.001$, Figure $3 \mathrm{~A}-\mathrm{C})$. However, no remarkable difference was found between the two groups in terms of PAS staining (Figure 4).

Hypothyroidism Leads to Enhanced Germ Cell Apoptosis in Mice Testis

The data analysis demonstrated that the spermatogonia,
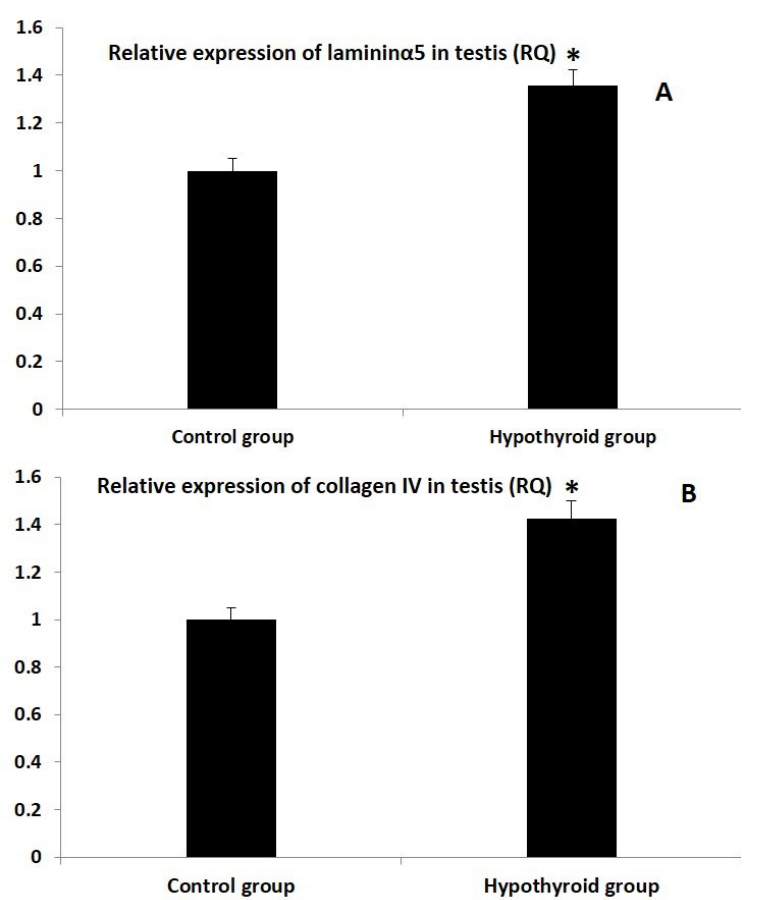

Figure 1. Comparison Between Laminin $\alpha 5$ (A) and Collagen IV (B) mRNA Level Expression in the Hypothyroid Group Compared to the Control Group Note. SD: Standard deviation. Values are expressed as the mean \pm SD. "Significant differences compared to the control group $(P<0.05)$.
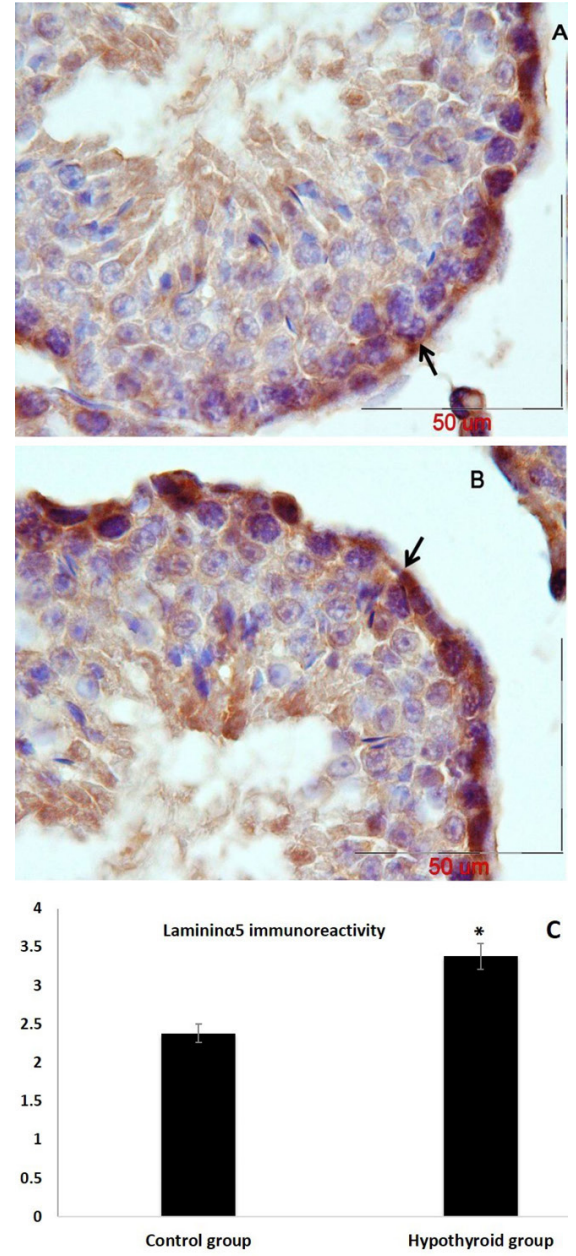

Figure 2. Qualitative and Quantitative Analysis of Immunohistochemical Staining for Laminin $\alpha 5$ Protein in the BM of Seminiferous Tubules: Representative Photomicrographs of Control (A) and Hypothyroid Groups (B) and a Graph (C) of Laminin $\alpha 5$ Staining Intensity.

Note. Positive immunoreaction is shown in different brown colors (Arrows). Scale bar $=50 \mu \mathrm{m} .{ }^{*}$ Statistical significance compared to the control group $(P<0.05)$.

primary spermatocytes, and spermatids underwent apoptosis. Based on the results, the mean number of TUNEL (+) spermatogonia and primary spermatocytes was significantly higher in the hypothyroid group compared to the controls $(P<0.001)$. A notable increase was also observed in the number of TUNEL (+) spermatid cells in the hypothyroid group when compared to the control group $(P<0.01$, Figures 5 and 6$)$.

Effect of Hypothyroidism on MDA and Thiol Contents and SOD Activity in the Mice Testis

The findings represented that PTU exposure increased MDA concentration in the testes of the hypothyroid group compared to the control group $(P<0.05$, Table 3$)$. Furthermore, SOD activity reduced in the hypothyroid group in comparison to the control group $(P<0.05$, Table 3 ). However, no significant difference was detected in any of the two groups regarding the thiol content. 


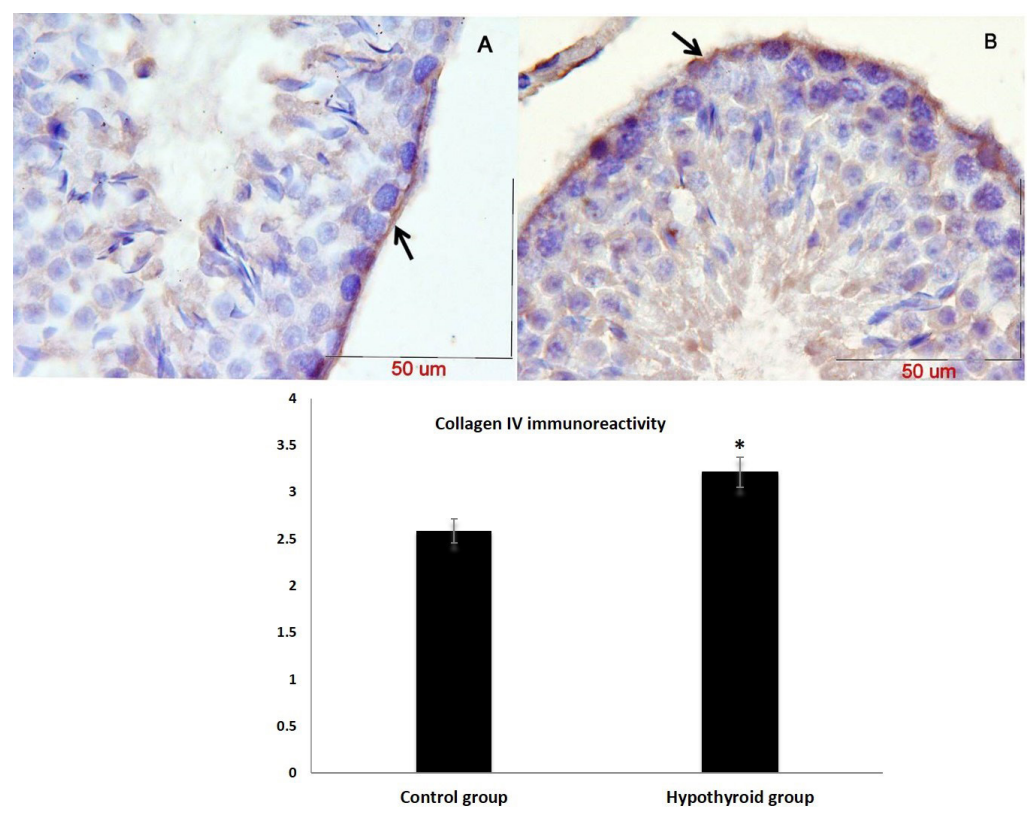

Figure 3. Qualitative and Quantitative Analysis of Immunohistochemical Staining for Collagen IV Protein in the BM of Seminiferous Tubules: Representative Photomicrographs of Control (A) and Hypothyroid Groups (B) and a Graph (C) of Collagen IV Staining Intensity.

Note. Positive immunoreaction is represented in different brown colors (Arrows). Scale bar $=50 \mu \mathrm{m}$. : Statistical significance compared to the control group $(P$ $<0.05)$.

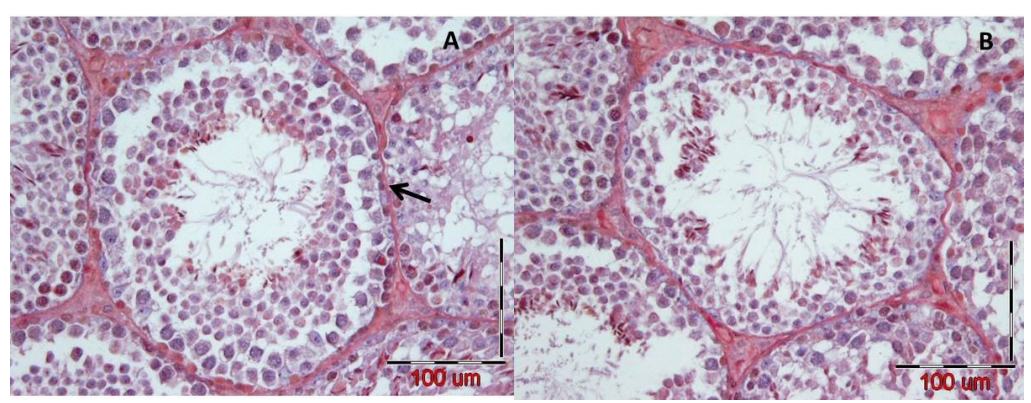

Figure 4. Photomicrograph Shows the BM of Seminiferous Tubules With PAS Staining (Arrow) in Control (A) and Hypothyroid (B) Groups. Note. Scale bar = 100 $\mu \mathrm{m}$; BM: Basement membrane; PAS: Periodic acid-Schiff.

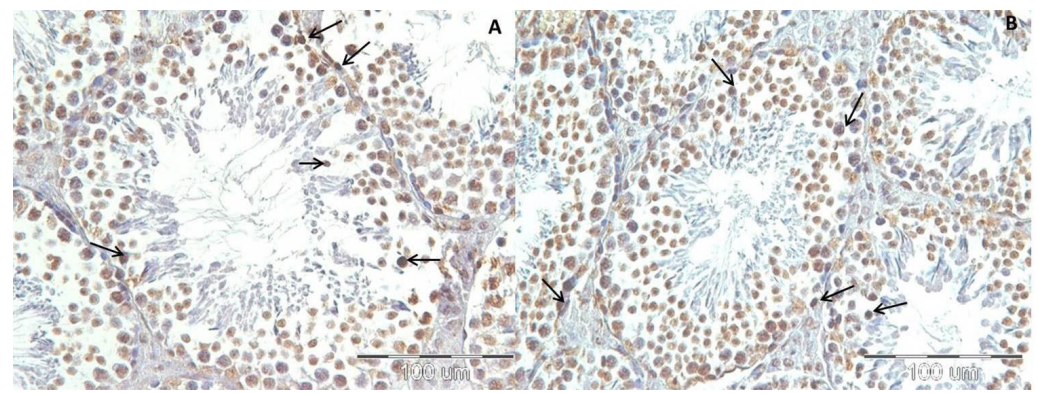

Figure 5. Photomicrographs Represents the Visualized Apoptotic Cells Using TUNEL Assay.

Note. TUNEL: Terminal transferase-mediated dUTP nick-end labelling. Arrows indicate the apoptotic germ cells in the seminiferous tubules of the control (A) and hypothyroid (B) groups. Scale bar $=100 \mu \mathrm{m}$.

\section{Discussion}

It is now widely accepted that hypothyroidism considerably impacts reproductive function in both genders (8). The clinical literature of the last decades has indicated that $\mathrm{TH}$ deficiency is related to abnormalities in the function and morphology of the testis and alterations in sexual activity
(38). Congenital and early childhood hypothyroidism has also been proved to cause significant health problems in men (10). Furthermore, ECM components, including BM, play a crucial role in tissue differentiation, development, and functions (21). The results also showed that $\mathrm{TH}$ regulates the expression of ECM components at both 
Table 3. Effect of Hypothyroidism on MDA, Thiol, and SOD Levels

\begin{tabular}{lll}
\hline Variables & Control & Hypothyroid \\
\hline MDA (nmol/mg protein) & $26.78 \pm 1.95$ & $31.07 \pm 1.56^{\mathrm{a}}$ \\
Thiol (microlmol/mg protein) & $0.61 \pm 0.16$ & $0.83 \pm 0.11$ \\
SOD (U/mg protein) & $6.61 \pm 0.48$ & $3.1 \pm 0.19^{\mathrm{a}}$ \\
\hline
\end{tabular}

SD: Standard deviation; MDA: Malondialdehyde; SOD: Superoxide dismutase.

a represents significant difference between hypothyroid and control groups $P$ value $<0.05$. Data are presented as mean \pm SD.

mRNA and protein levels in human and rat tissues (20). The in vivo transfer of laminin and collagen antibodies against the $\mathrm{BM}$ of the seminiferous tubule has been demonstrated perturbations in spermatogenesis and Sertoli cell functions (23). The results of Loveland et al demonstrated a direct correlation between developmental changes in the $\mathrm{BM}$ composition and delay in the development of germ and Sertoli cell maturation in the testis of the hypothyroid rats (19). Furthermore, in one study, hypothyroid status caused a marked disruption in the architecture of the ECM of tendons (24). There was a significant increase in laminin $\alpha 5$ and collagen IV expression at both mRNA and protein levels due to $\mathrm{TH}$ deficiency in the present study. Consistent with our findings, Amerion et al reported that hypothyroid state during pregnancy caused a significant increase in laminin immunoreactivity in rat newborns' skin (39). Despite these results, Hushmand et al found a significant reduction in the laminin reaction of the lung alveoli in the hypothyroid group (40), which is inconsistent with the results of this study. In several cases of impaired spermatogenesis, the lamina propria of seminiferous tubules considerably thickened by an increase in the ECM components $(11,18)$. Fibroblast proliferation, tubular wall hyaline, interstitial edema, and peripheral fibrosis, as well as tubular BM adhesion have also been observed in patients with hypothyroidism (38). Although the BM of the seminiferous tubules showed a positive reaction to PAS staining in the present study, no significant difference was found in the intensity and thickness of the $\mathrm{BM}$ between the hypothyroid and control groups. Some studies represented that BM degradation by PAS staining is not clearly detectable, and reticulin staining has more potential to show BM changes (41). Finally, the results revealed that hypothyroidism by increasing the synthesis of BM components or reducing their turnover could increase the thickness of the BM (39). Thus, alterations in the BM components affect the function and structure of the BM, which can negatively affect the spermatogenesis process (20).

Germ cell apoptosis in mammals is crucial to control the correct number of these cells during spermatogenesis (25). Although TH is considered not to act directly on the apoptosis of germ cells, it may control germ cell apoptosis via affecting the Sertoli cell (3). Moreover, the antiapoptotic role of $\mathrm{T} 3$ and $\mathrm{T} 4$ has been reported in some tissues such as tenocytes (24). A dearth of information exists on germ cell apoptosis caused by hypothyroidism. In the present study, significant apoptosis was observed in the germ cells of hypothyroid mice rather than the control ones. These findings are in line with the findings of Sahoo et al, indicating an increase in the number of apoptotic germ cells following the postnatal hypothyroidism of the rat testis (27). In another study, exposure to PTU in the postnatal period led to massive germ cell death (42). Additionally, apoptotic changes have been reported in the epididymal mitochondria of hypothyroid rats (43). Testicular torsion also increased the index of apoptosis and caspase- 3 level while the administration of Rapamycin during testicular torsion decreased the damage of the cell (44).

Furthermore, Shokoohi et al found an increase in the index of apoptosis and Bax expression in the torsion/

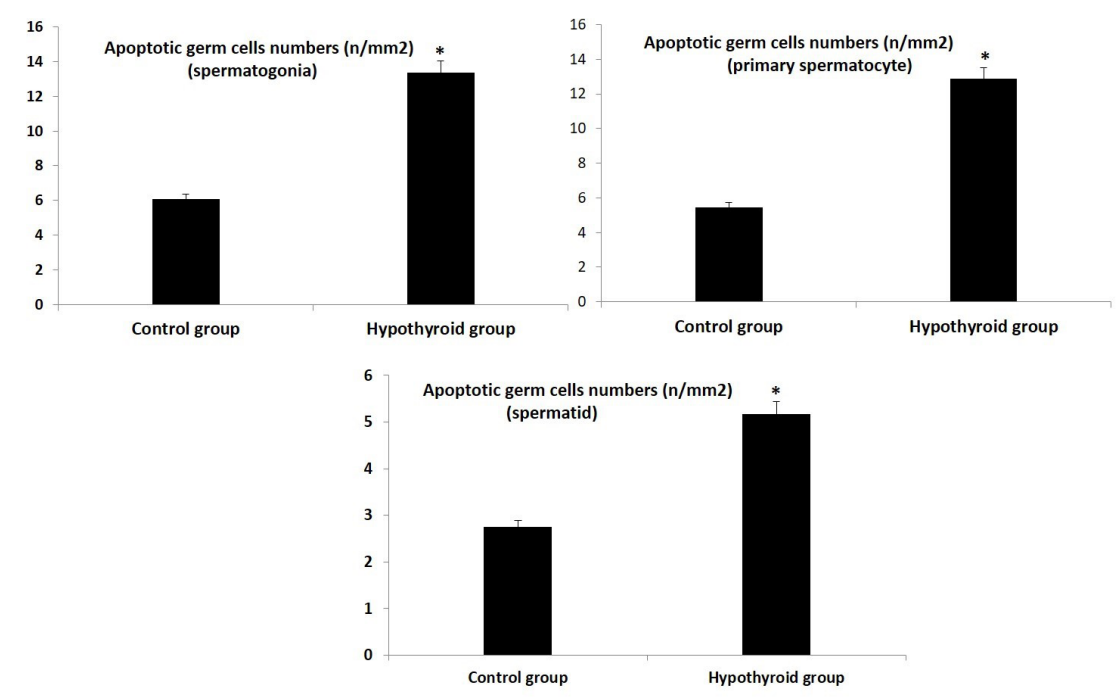

Figure 6. Graph Illustrates the Quantitative Analysis of the Apoptotic Germ Cells in the Control and Hypothyroid Groups.

Note. SD: standard deviation. Values are expressed as the mean \pm SD. ${ }^{*}$ Significant differences compared to the control group $(P<0.05)$. 
detorsion rat model, and the administration of the hydroalcoholic extract of Fumaria parviflora increased the gene expression of $B c l-2$ (45).

The TH level alteration has been considered to affect the functions of animal tissues by modulating their antioxidant defense systems (26). It is now well established that TH plays a crucial role in maintaining the balance between ROS and antioxidant defense molecules $(32,46,47)$, and one of the possible mechanisms responsible for testis dysfunctions in hypothyroidism, at least, seems to be due to an increase in the OS status $(36,48)$. Human studies have confirmed that there is an increase in OS in the male reproductive system in both hyperthyroidism and hypothyroidism (10). The testis is more prone to oxidative damage since it is rich in polyunsaturated fatty acids and has enzymatic and non-enzymatic antioxidant defense systems $(26,32)$. In this research, there was a significant increase in LPx levels whereas a decrease in the activity of antioxidant enzymes. According to Nath et al, ROS increased the mRNA expressions of type III and IV collagen in rat kidneys (49). In addition, $\mathrm{H}_{2} \mathrm{O}_{2}$ upregulated the vascular endothelial genes in rat heart endothelium (50). In this study, a significant increase was observed in the expressions of collagen IV and laminin mRNAs in response to hypothyroidism, which might be due to a rise in ROS induced by hypothyroidism. Moreover, the results of biochemical parameters showed a significant reduction in the SOD activity of the hypothyroid group accompanied by an increase in the MDA level. In support of our results, some studies reported that the hypothyroid condition changes the antioxidant status activity in several tissues $(26,31,36,48)$. Our finding corroborates with the elevated LPx and reduced SOD activity in rat testis following hypothyroidism $(26,27,32)$. The comparison of SOD activity in groups demonstrated that SOD activity was significantly lower in the hypothyroid group compared to the control group (51). In another study, PTU administration decreased SOD activity and thiol content in the cerebellar tissue by increasing MDA levels. SOD is considered to be the first line of the cellular antioxidant defense system, and decreased SOD activity with hypothyroidism may be accompanied by an increase in $\mathrm{O}_{2}^{-}$, which ultimately increases LPx (36).

Based on the evidence, a rational relationship exists between the increase in the MDA levels and the decline in the SOD activity following hypothyroidism (52). In this respect, clinical literature has also shown that SOD activity was significantly lower in patients with hypothyroidism while the MDA level was higher (36). High LPx and low glutathione and SOD levels have been reported in transient and hypothyroid states (26). In the research conducted by Shokoohi et al, testis torsion increased the MDA level whereas decreasing glutathione peroxidase (GPx) and SOD levels, and treatment with the hydroalcoholic extract of Fumaria parviflora significantly increased the level of these antioxidant enzymes (45). Similarly, Soltani et al demonstrated a significant elevation in the MDA levels of the testis torsion/detorsion rat model while a reduction in SOD and GPx activities. However, Matricaria chamomilla extract treatment significantly increased SOD and GPx while decreasing the levels of MDA (53). OS has been considered as one of the significant factors inducing germ cell apoptosis (54). Hence, the triggered apoptosis in our study may be due to the high level of OS under hypothyroidism and the limited antioxidant defense system in the testis. Chronic ethanol administration was indicated to increase the OS of the testis either due to an increase in LPx or deficiency in the antioxidant defense system, leading to induced germ cell apoptosis (54). The increased OS level due to exposure to bisphenol A leads to an increase in the number of TUNEL-positive testicular germ cells (55). Thus, hypothyroidism can cause germ cell apoptosis either by increasing OS or altering the expression of BM components.

\section{Conclusions}

To sum up, disturbance in the BM components of seminiferous tubules and increased germ cell apoptosis might be due to the increased OS and diminished antioxidant capacity in the hypothyroid condition. However, further investigations are needed in this context.

\section{Limitation of the Study}

The BM of seminiferous tubules showed a positive reaction to PAS staining. However, there was no significant difference in BM severity and thickness between the hypothyroid and control groups. Therefore, reticulin staining was one of the limitations of the study.

\begin{abstract}
Authors' Contribution
$\mathrm{JM}, \mathrm{NMR}, \mathrm{AF}$, and $\mathrm{KE}$ conceived the presented idea, designed the experiments, and approved the final version of the manuscript. AF and $\mathrm{KE}$ conducted the experiments, processed the experimental data, and performed the analysis. JM and NMR. conducted histological techniques and supervised the project. SM used a molecular technique and approved the final version of the manuscript. AF drafted the manuscript and designed the figures. NMR and JM revised and approved the final version of the manuscript. Finally, FAR helped supervise the project and approved the final version of the manuscript.
\end{abstract}

\section{Conflict of Interests}

Authors have no conflict of interests.

\section{Ethical Issues}

The Ethical Committee approved this work in all research stages at Mashhad University of Medical Sciences, Mashhad, Iran.

\section{Financial Support}

This research project (No. 931752) was financially supported by the Vice-Chancellor for the Research of Mashhad University of Medical Sciences, Mashhad, Iran.

\section{Acknowledgments}

The results of the present study are based on a Ph.D. student thesis. The authors would like to thank Mrs. F. Motejadded, Mrs. F. Tajik, 
and Mrs. A. Amini for their technical assistance.

\section{References}

1. Gao Y, Lee WM, Cheng CY. Thyroid hormone function in the rat testis. Front Endocrinol (Lausanne). 2014;5:188. doi:10.3389/ fendo.2014.00188

2. Krassas GE, Poppe K, Glinoer D. Thyroid function and human reproductive health. Endocr Rev. 2010;31(5):702-755. doi:10.1210/er.2009-0041

3. Kumar A, Shekhar S, Dhole B. Thyroid and male reproduction. Indian J Endocrinol Metab. 2014;18(1):23-31. doi:10.4103/2230-8210.126523

4. Hassan A, Altamirano-Ufion A, Zulfiqar B, Boddu P. Subclinical hypothyroidism and its association with increased cardiovascular mortality: call for action. Cardiol Res. 2017;8(2):31-35. doi:10.14740/cr524w

5. Bensenor IM, Olmos RD, Lotufo PA. Hypothyroidism in the elderly: diagnosis and management. Clin Interv Aging. 2012;7:97-111. doi:10.2147/cia.s23966

6. Gesing A, Lewiński A, Karbownik-Lewińska M. The thyroid gland and the process of aging; what is new? Thyroid Res. 2012;5(1):16. doi:10.1186/1756-6614-5-16

7. Kostoglou-Athanassiou I, Ntalles K. Hypothyroidism - new aspects of an old disease. Hippokratia. 2010;14(2):82-87.

8. Dittrich R, Beckmann MW, Oppelt PG, et al. Thyroid hormone receptors and reproduction. J Reprod Immunol. 2011;90(1):5866. doi:10.1016/j.jri.2011.02.009

9. Wagner MS, Wajner SM, Maia AL. The role of thyroid hormone in testicular development and function. J Endocrinol. 2008;199(3):351-365. doi:10.1677/joe-08-0218

10. Singh R, J Hamada A, Agarwal A. Thyroid hormones in male reproduction and fertility. Open Reprod Sci J. 2011;3:98-104. doi:10.2174/1874255601103010098

11. Buzzard JJ, Morrison JR, O'Bryan MK, Song Q, Wreford NG. Developmental expression of thyroid hormone receptors in the rat testis. Biol Reprod. 2000;62(3):664-669. doi:10.1095/ biolreprod62.3.664

12. Enders GC, Kahsai TZ, Lian G, Funabiki K, Killen PD, Hudson BG. Developmental changes in seminiferous tubule extracellular matrix components of the mouse testis: alpha 3(IV) collagen chain expressed at the initiation of spermatogenesis. Biol Reprod. 1995;53(6):1489-1499. doi:10.1095/biolreprod53.6.1489

13. Hadley MA, Byers SW, Suárez-Quian CA, Kleinman HK, Dym M. Extracellular matrix regulates Sertoli cell differentiation, testicular cord formation, and germ cell development in vitro. J Cell Biol. 1985;101(4):1511-1522. doi:10.1083/ jcb.101.4.1511

14. Siu MK, Cheng CY. Extracellular matrix: recent advances on its role in junction dynamics in the seminiferous epithelium during spermatogenesis. Biol Reprod. 2004;71(2):375-391. doi:10.1095/biolreprod.104.028225

15. Siu MK, Cheng CY. Extracellular matrix and its role in spermatogenesis. Adv Exp Med Biol. 2008;636:74-91. doi:10.1007/978-0-387-09597-4_5

16. Yazama F, Esaki M, Sawada H. Immunocytochemistry of extracellular matrix components in the rat seminiferous tubule: electron microscopic localization with improved methodology. Anat Rec. 1997;248(1):51-62. doi:10.1002/ (sici)1097-0185(199705)248:1<51::aid-ar6>3.0.co;2-i

17. Davis CM, Papadopoulos V, Sommers CL, Kleinman HK, Dym M. Differential expression of extracellular matrix components in rat Sertoli cells. Biol Reprod. 1990;43(5):860-869. doi:10.1095/biolreprod43.5.860

18. Gülkesen KH, Erdoğru T, Sargin CF, Karpuzoğlu G. Expression of extracellular matrix proteins and vimentin in testes of azoospermic man: an immunohistochemical and morphometric study. Asian J Androl. 2002;4(1):55-60.

19. Loveland K, Schlatt S, Sasaki T, Chu ML, Timpl R, Dziadek M. Developmental changes in the basement membrane of the normal and hypothyroid postnatal rat testis: segmental localization of fibulin-2 and fibronectin. Biol Reprod. 1998;58(5):1123-1130. doi:10.1095/biolreprod58.5.1123

20. Ulisse S, Rucci N, Piersanti D, et al. Regulation by thyroid hormone of the expression of basement membrane components in rat prepubertal Sertoli cells. Endocrinology. 1998;139(2):741-747. doi:10.1210/endo.139.2.5732

21. Hadley MA, Dym M. Immunocytochemistry of extracellular matrix in the lamina propria of the rat testis: electron microscopic localization. Biol Reprod. 1987;37(5):12831289. doi:10.1095/biolreprod37.5.1283

22. Rafighdost $H$, Nikravesh MR, Jalali M. Pattern of laminin expression during kidney morphogenesis in Balb/c mice. Pak J Biol Sci. 2010;13(19):961-965. doi:10.3923/ pjbs.2010.961.965

23. Siu MK, Cheng CY. Dynamic cross-talk between cells and the extracellular matrix in the testis. Bioessays. 2004;26(9):978992. doi:10.1002/bies.20099

24. Oliva F, Piccirilli E, Berardi AC, Tarantino U, Maffulli N. Influence of thyroid hormones on tendon homeostasis. Adv Exp Med Biol. 2016;920:133-138. doi:10.1007/978-3-31933943-6 12

25. Silva D, Lizama C, Tapia V, Moreno RD. Propylthiouracilinduced hypothyroidism delays apoptosis during the first wave of spermatogenesis. Biol Res. 2011;44(2):181-188. doi:10.4067/s0716-97602011000200010

26. Sahoo DK, Roy A, Bhanja S, Chainy GB. Hypothyroidism impairs antioxidant defence system and testicular physiology during development and maturation. Gen Comp Endocrinol. 2008;156(1):63-70. doi:10.1016/j.ygcen.2007.11.007

27. Sahoo DK. Increased germ cell apoptosis during testicular development and maturation by experimentally induced transient and persistent hypothyroidism. WebmedCentral APOPTOSIS. 2013;4(5):WMC004235. doi:10.9754/journal. wmc. 2013.004235

28. Aitken RJ, Findlay JK, Hutt KJ, Kerr JB. Apoptosis in the germ line. Reproduction. 2011;141(2):139-150. doi:10.1530/rep10-0232

29. Singh R, Upadhyay G, Kumar S, et al. Hypothyroidism alters the expression of $\mathrm{Bcl}-2$ family genes to induce enhanced apoptosis in the developing cerebellum. J Endocrinol. 2003;176(1):39-46. doi:10.1677/joe.0.1760039

30. Singh R, Upadhyay G, Godbole MM. Hypothyroidism alters mitochondrial morphology and induces release of apoptogenic proteins during rat cerebellar development. J Endocrinol. 2003;176(3):321-329. doi:10.1677/joe.0.1760321

31. Chattopadhyay S, Choudhury S, Roy A, Chainy GB, Samanta L. T3 fails to restore mitochondrial thiol redox status altered by experimental hypothyroidism in rat testis. Gen Comp Endocrinol. 2010;169(1):39-47. doi:10.1016/j. ygcen.2010.07.014

32. Sahoo DK, Roy A. Compromised rat testicular antioxidan defence system by hypothyroidism before puberty. Int Endocrinol. 2012;2012:637825. doi:10.1155/2012/637825

33. Aldaghi MR, Sankian M, Sameni HR, Safari M. Effects of Alpha Lipoic Acid Treatment on Laminin Alteration of the Sciatic Nerve in Streptozotocin Induced Diabetic Rats. Middle East J Rehabil Health Stud. 2014;1(2):e23471. doi:10.17795/ mejrh-23471

34. Pujar A, Pereira T, Tamgadge A, Bhalerao S, Tamgadge S Comparing the efficacy of hematoxylin and eosin, periodic acid schiff and fluorescent periodic acid schiff-acriflavine 
techniques for demonstration of basement membrane in oral lichen planus: a histochemical study. Indian J Dermatol. 2015;60(5):450-456. doi:10.4103/0019-5154.159626

35. Ebrahimzadeh-Bideskan AR, Hami J, Alipour F, Haghir H, Fazel AR, Sadeghi A. Protective effects of ascorbic acid and garlic extract against lead-induced apoptosis in developing rat hippocampus. Metab Brain Dis. 2016;31(5):1123-1132. doi:10.1007/s11011-016-9837-7

36. Baghcheghi Y, Beheshti F, Salmani H, Soukhtanloo M, Hosseini M. Protective effect of PPARy agonists on cerebellar tissues oxidative damage in hypothyroid rats. Neurol Res Int. 2016;2016:1952561. doi:10.1155/2016/1952561

37. Madesh M, Balasubramanian KA. Microtiter plate assay for superoxide dismutase using MTT reduction by superoxide. Indian J Biochem Biophys. 1998;35(3):184-188.

38. Wajner SM, Wagner MS, Maia AL. Clinical implications of altered thyroid status in male testicular function. Arq Bras Endocrinol Metabol. 2009;53(8):976-982. doi:10.1590/ s0004-27302009000800011

39. Amerion M, Tahajjodi S, Hushmand Z, Mahdavi Shahri N, Nikravesh MR, Jalali M. The effect of maternal thyroid disorders (hypothyroidism and hyperthyroidism) during pregnancy and lactation on skin development in Wistar rat newborns. Iran J Basic Med Sci. 2013;16(5):665-674.

40. Hushmand Z, Amerion M, Mahdavi Shahri N, Nikravesh MR, Jalali M. Immunohistochemical evaluation of the effects of maternal hypothyroidism during pregnancy and lactation on the expression of laminin in the lung alveoli of newborn Wistar rats. Journal of Cell \& Tissue. 2015;5(4):379-384. doi:10.29252/jct.5.4.379

41. Yamasaki M, Ueda G, Inoue M, TanakaY, Kurachi K. Correlative light and immunohistological study of the basement membrane of the human squamous cervical carcinoma. Nihon Sanka Fujinka Gakkai Zasshi. 1980;32(11):1859-1864.

42. Santos-Ahmed J, Brown C, Smith SD, et al. Akt1 protects against germ cell apoptosis in the postnatal mouse testis following lactational exposure to 6-N-propylthiouracil. Reprod Toxicol. 2011;31(1):17-25. doi:10.1016/j.reprotox.2010.09.012

43. Palaoro LA, Rocher AE, Canessa OE, et al. Epididymal mitochondrial status of hypothyroid rats examined by transmission electron microscopy. Biotech Histochem. 2013;88(3-4):138-144. doi:10.3109/10520295.2012.741712

44. Ghasemnejad-Berenji M, Ghazi-Khansari M, Yazdani I, et al. Rapamycin protects testes against germ cell apoptosis and oxidative stress induced by testicular ischemia-reperfusion. Iran J Basic Med Sci. 2017;20(8):905-911. doi:10.22038/ ijbms.2017.9112

45. Shokoohi M, Shoorei H, Soltani M, Abtahi-Eivari SH,
Salimnejad R, Moghimian M. Protective effects of the hydroalcoholic extract of Fumaria parviflora on testicular injury induced by torsion/detorsion in adult rats. Andrologia. 2018;50(7):e13047. doi:10.1111/and.13047

46. Choudhury S, Chainy GB, Mishro MM. Experimentally induced hypo- and hyper-thyroidism influence on the antioxidant defence system in adult rat testis. Andrologia. 2003;35(3):131-140. doi:10.1046/j.1439-0272.2003.00548.x

47. Chakraborty A, Mandal J, Mondal C, Sinha S, Chandra AK. Effect of excess iodine on oxidative stress markers, steroidogenicenzyme activities, testicular morphology, and functions in adult male rats. Biol Trace Elem Res. 2016;172(2):380-394. doi:10.1007/s12011-015-0581-3

48. Baghcheghi Y, Salmani H, Beheshti F, Hosseini M. Contribution of brain tissue oxidative damage in hypothyroidism-associated learning and memory impairments. Adv Biomed Res. 2017;6:59. doi:10.4103/2277-9175.206699

49. Nath KA, Grande J, Croatt A, Haugen J, Kim Y, Rosenberg ME. Redox regulation of renal DNA synthesis, transforming growth factor-beta1 and collagen gene expression. Kidney Int. 1998;53(2):367-381. doi:10.1046/j.1523-1755.1998.00778.x

50. Chua CC, Hamdy RC, Chua BH. Upregulation of vascular endothelial growth factor by $\mathrm{H} 2 \mathrm{O} 2$ in rat heart endothelial cells. Free Radic Biol Med. 1998;25(8):891-897. doi:10.1016/ s0891-5849(98)00115-4

51. Zamoner A, Barreto KP, Filho DW, et al. Propylthiouracilinduced congenital hypothyroidism upregulates vimentin phosphorylation and depletes antioxidant defenses in immature rat testis. J Mol Endocrinol. 2008;40(3):125-135. doi:10.1677/jme-07-0089

52. Pan T, Zhong M, Zhong X, Zhang Y, Zhu D. Levothyroxine replacement therapy with vitamin $E$ supplementation prevents oxidative stress and cognitive deficit in experimental hypothyroidism. Endocrine. 2013;43(2):434-439. doi:10.1007/s12020-012-9801-1

53. Soltani M, Moghimian M, Abtahi-Eivari SH, Shoorei $H$, Khaki A, Shokoohi M. Protective effects of matricaria chamomilla extract on torsion/ detorsion-induced tissue damage and oxidative stress in adult rat testis. Int J Fertil Steril. 2018;12(3):242-248. doi:10.22074/ijfs.2018.5324

54. Maneesh M, Jayalekshmi H, Dutta S, Chakrabarti A, Vasudevan DM. Role of oxidative stress in ethanol induced germ cell apoptosis - an experimental study in rats. Indian J Clin Biochem. 2005;20(2):62-67. doi:10.1007/bf02867402

55. Kaur S, Saluja M, Bansal MP. Bisphenol A induced oxidative stress and apoptosis in mice testes: modulation by selenium. Andrologia. 2018;50(3). doi:10.1111/and.12834

Copyright $\odot 2022$ The Author(s); This is an open-access article distributed under the terms of the Creative Commons Attribution License (http://creativecommons.org/licenses/by/4.0), which permits unrestricted use, distribution, and reproduction in any medium, provided the original work is properly cited. 